\title{
Carcinogenic risk assessment of benzene from the oil and gas field.
}

\author{
Kenessary DU*, Kenessary AU, Kenessariyev UI, Kurmangaliev OM \\ Kazakh National Medical University, Almaty, Republic of Kazakhstan
}

\begin{abstract}
Introduction and objective: In 2012 actual concentrations of benzene in the villages (9,000 people) near one of the largest in the world oil and gas condensate fields (Kazakhstan, Central Asia) were several times higher than expected model-based concentrations. Therefore a human health risk assessment from benzene was made with a focus on carcinogenic incidence determination. Additional cancer cases were derived from the benzene concentrations and turned into an economic damage to the state.
\end{abstract}

Materials and methods: Annual population cancerogenic risk was derived with the use of Human health risk assessment methodology as described in the Guidance by Rahmanin et al. Economic damage from additional cancer cases was defined with a newly developed method with socio-economic characteristics of Kazakhstan taken into account.

Results: In 2012, additional carcinogenic morbidity from benzene emissions totaled 0.1 case per $\mathbf{9 , 0 0 0}$ people. Human health economic damage from benzene caused by the activity of the abovementioned facility was estimated at $\$ \mathbf{\$ 4 3 3 0}$.

As seen from this exact study, the results of modeling and monitoring of one and the same facility may greatly differ. Therefore holding the cancerogenic risk assessment on an annual basis is a necessity and it must be made mandatorily, on a legal basis, not only in this exact region, but whenever an industrial facility runs its operations associated with the air pollution.

Keywords: Human health, carcinogen, risk assessment, economic damage, benzene, Kazakhstan.

Accepted on December 18, 2017

\section{Introduction}

The oil industry is the so-called driving force of Kazakhstani (RoK) economy, a post-soviet Central Asian country. And the Karachaganak oil and gas condensate field (KOGCF), situated in the country's western part, is one of the world's biggest oil fields with approximately 1.2 billion tons of estimated oil reserves only.

In view of continuous emissions of combustion products from the field, the air quality and human health have been continuously monitored since last 20 years [1-3]. But the carcinogenic impact on human health from the facility emissions has never been in a focus, although cancer incidence in the RoK is increasing rapidly.

Human health risk assessment from chemicals, as described in the Guidance by Rahmanin et al., that enables to derive additional carcinogenic incidence from concentrations of chemicals in air, is still poorly represented in the domestic legal and regulatory documentation [4]. The only significant official document presented in the local legislation is the RoK Governmental Resolution, which decrees that sanitary protection zones for facilities under 1 st or 2 nd hazard class may not be definitively delineated until after the human health risk has been assessed [5].

The first human health risk assessment attempt in KOGCF region was made by Kenessary A.U. in 2011 in his dissertational work for Master degree. His research was based on a facility emissions modeling. As a result 8 priority substances were derived from the facility emissions into the air, including benzene [6]. Benzene is a well-established human carcinogen. There have been numerous epidemiological studies on the effects of benzene, most of which have dealt with chronic industrial exposures. The most consistent evidence for a causal association in humans has been found between benzene exposure and various types of leukaemia. Increased leukemia risk was identified inter alia in studies of chemical workers and workers in oil refineries $[7,8]$. A Danish study of children's traffic-related exposures by Raaschou-Nielsen et al. (2001) found a near-significant $25 \%$ increased risk of lymphomas for a doubling of the concentration of benzene during pregnancy [9]. Kazazyan and Reshetin have stated that approximately 2,000-4,000 people in Russia annually have cancer due to "carcinogens present in the atmosphere", among which benzene makes the greatest contribution to the cancer incidence (66.2\%) [10].

Later on full cycle of human health risk assessment from the KOGCF emission was done by Kenessariyev et al. in the same year. As with the previous research (Kenessary A.U.) the data was derived from the modeling results. As a result, none of the carcinogenic substances (including benzene) was included into the priority list due to insufficient emissions share (less than $1 \%$ ) and acceptable individual carcinogenic risk (for a lifetime period of 70 years) - less than 1 case in a million (less than $\leq$ $1.0 \mathrm{E}-06)$, from 1.54 cases per 100 million people to 7.71 cases per 10 million people (1.54E-08-7.71E-07) [11]. 
Finally the full annual (2012) cycle of observations in the nearby villages $(9,000$ inhabitats), made by Gidromet lab., revealed a different picture. According to their data the actual benzene concentrations $\left(0.1 \mathrm{mg} / \mathrm{m}^{3}\right)$ were much higher than the modelbased $\left(0.0001 \mathrm{mg} / \mathrm{m}^{3}\right)$, which became the reason for the present investigations [12].

\section{Materials and Methods}

As the objective of the study was to measure the human health effect of air pollution, full annual cycle field observations of benzene were provided by the Hydromet LTD laboratory, which had performed environmental monitoring at the above mentioned villages.

\section{The Hydromet LTD laboratory}

The Hydromet LTD lab is accredited by the RoK State Standard. The Company collects samples afield and analyzes them in a stationary laboratory. At the KOGCF SPZ boundary the air is sampled 4 times a day (at 1:00 AM, 7:00 AM, 1:00 PM, and 7:00 PM). However, the obtained results (of sample collection, storage, transportation and laboratory analysis) bear higher error probability (human factor) comparative to results of measurements and analysis obtained in automated mode [12].

\section{Determination of carcinogenic risk}

According to the above mentioned Guidance the main carcinogenic risk assessment parameter is a so called slope factor (SF). Cancer slope factors are used to estimate the risk of cancer associated with exposure to a carcinogenic or potentially carcinogenic substance. A slope factor is an upper bound, approximating a $95 \%$ confidence limit, on the increased cancer risk from a lifetime (70 years) exposure to an agent by ingestion (SFo) or inhalation (SFi) as in our case. This estimate, usually expressed in units of proportion (of a population) affected per $\mathrm{mg}$ of substance $/ \mathrm{kg}$ body weight-day, is generally reserved for use in the low-dose region of the dose-response relationship, that is, for exposures corresponding to risks less than 1 in 100 [13]. In our case SFi for benzene is equal 0.027 [4].

Another carcinogenic risk assessment parameter is the inhalation unit risk (URi) that is the upper-bound excess lifetime cancer risk estimated to result from continuous exposure to an agent at a concentration of $1 \mu \mathrm{g} / \mathrm{m}^{3}$ in air [13]. URi is counted with the use of SFi and standard values for human body weight (70 kg), as well as daily air intake $\left(20 \mathrm{~m}^{3} /\right.$ day $)$ :

$U R i=S F i \times 20 / 70[4]$.

Annual population carcinogenic risk (PCRa) is the estimated number of additional cancer cases during a given year. In our case this value was calculated as follows:

$P C R a=(C \times U R i) \times P O P / 70[4]$,

where:

$C$ - average annual concentration of benzene, $\mathrm{mg} / \mathrm{m}^{3}$;

$P O P$ - size of the population exposed, people;

$U R i$ - lifetime inhalation unit risk (70 years), $\mathrm{mg} / \mathrm{m}^{3}$.

\section{Economic damage evaluation}

With socio-economic characteristics of Kazakhstan taken into account, the methodology for calculating the economic damage to the state from additional cancer cases was tested for the very first time in this study. This methodology is based on a phased assessment of economic damage depending on the stage of a disease, including the cost of treatment within the state benefit package, the average duration of temporary disability owing to illness, and as a result- the total loss incurred by the state because of under collected GDP due to temporary disability, as well as the social benefits payments:

$\mathrm{EDmorb}=\mathrm{TC}+\mathrm{SIC}+\mathrm{SSC}+\mathrm{LGDP}$

where:

TC - money spent on cancer cases treatment;

SIC - sick leave payment;

SSC - payment of the total amount of Social security disability welfare;

LGDP - cumulative losses of the state because of shortfalls in GDP due to temporary disability from cancer.

It should be noticed that the government losses on cancer cases treatment must be counted separately for each stage of development of cancer incidence (1-4). Therefore the total losses are a sum of all stages:

TC=stage $1+$ stage $2+$ stage $3+$ stage 4

Money spent on cancer cases treatment at exact stage are a multiplication of state expenses for 1 case treatment at certain $x$ stage $\left(\mathrm{TC}_{\mathrm{cx}}\right)$ by PCRa, with an adjustment factor reflecting the number of registered cancer patients at this exact stage of disease among the population exposed $\left(\mathrm{k}_{\mathrm{cx}}=\right.$ number of cancer patients registered at $x$ stage $\left(\mathrm{q}_{\text {cancer }} \mathrm{x}\right) /$ general number of registered cancer patients $\left.\left(\mathrm{q}_{\text {cancer }}\right)\right)$ :

stage $\mathrm{X}=\mathrm{TC}_{\mathrm{cx}} * \mathrm{PCRa}^{*} \mathrm{k}_{\mathrm{cx}}$

According to the RoK legislation sick leave payments cannot exceed 15 monthly calculation index (MCI) [14]. Due to prolonged treatment of cancer cases a maximum of MCI is taken into account $(15 \mathrm{MCI})$. Therefore sick leave payments are a multiplication of maximal sum of sick leave payment $\left(\mathrm{SIC}_{\max }\right)$ by PCRa:

$\mathrm{SIC}=\mathrm{SIC}_{\text {max }} * \mathrm{PCRa}$

Payments of the total amount of Social security disability welfare are a multiplication of the average annual cost of state social benefits $\left(b_{c}\right)$ by PCRa, with an adjustment factor reflecting the number of oncology disability benefit recipients $\left(\mathrm{k}_{\mathrm{cb}}\right)$ in the studied group:

\section{$\mathrm{SSC}=\mathrm{b}_{\mathrm{c}} * \mathrm{PCRa} * \mathrm{k}_{\mathrm{cb}}$}

Cumulative losses of the state because of shortfalls in GDP are a sum of state losses because of shortfalls in GDP at each exact stage of disease (LGDP $\left.{ }_{\text {cancer }} \mathrm{x}\right)$. This indicator is a multiplication per working capita GDP (CGDP ${ }_{w}$ ) by the number of lost months of working time due to disability from oncological diseases at exact stage $\left(\mathrm{m}_{\mathrm{cx}}\right)$, as well as by PCRa and $\mathrm{k}_{\mathrm{cx}}$ :

$\operatorname{LGDP}_{\text {cancer }} \mathrm{x}=\mathrm{CGDP}_{\mathrm{w}} * \mathrm{~m}_{\mathrm{cx}} * \mathrm{PCRa}^{*} \mathrm{k}_{\mathrm{cx}}$ 


\section{Results}

Slope factor index and calculated Unit inhalation risk, used in this study, was taken from the Russian Guidelines and therefore had to be checked for compliance with the international standards. Towards this end, we conferred these data to the world's most widely recognized official database. In particular, the benzene URi data was compared with the similar data presented by the Integrated risk information system (IRIS) [15]. The results of the comparison are shown in Table 1 below.

As seen from the table above, the benzene unit inhalation risk (URi) was shown in parts per $\mu \mathrm{g} / \mathrm{m}^{3}$, therefore we had to convert parts into per $\mathrm{mg} / \mathrm{m}^{3}$.

Judging from the comparison made, benzene has the same RfC values, both in Guidelines, and IRIS: $3.00 \mathrm{E}-02 \mathrm{mg} / \mathrm{m}^{3}$. The benzene URi in the Guidelines (7.71E-03 per $\left.\mathrm{mg} / \mathrm{m}^{3}\right)$ is within the permissible range of the URi values provided in the IRIS (2.20E-03 to $7.80 \mathrm{E}-03$ per $\left.\mathrm{mg} / \mathrm{m}^{3}\right)$. Thence, human health risk assessment results yielded by this study (which were based on use of inhalation unit risk provided by the Guidelines) are believed to be accurate.

So, with the Slope factor equal to 0.027 and a Unit inhalation risk calculated (0.008) Individual carcinogenic risk in the studied area was identified at the average of 7.8 cases per 10,000 people to 8.3 cases per 10,000 people (7.80E-04-8.30E-04), that is much higher when compared to the modeled results $(1.39 \mathrm{E}-07$ $-5.40 \mathrm{E}-08)$. Annual population carcinogenic risk was identified at the average of 0.02-0.05 cases. Total annual population cancer risk for the whole studied area was calculated at 0.1 cases, with a main contribution from Kiziltal village (0.05). Carcinogenic risk assessment results are summarized in Table 2.

Through use of a newly developed methodology for assessing economic damage from cancer incidence, the damage caused to the state from additional cancer cases resulting from the KOGCF benzene emissions totaled $\$ 4,530$ for 2012 with the main contribution from Kiziltal patients - \$2,100, and including Berezovka (\$844), Priuralni (\$689) and Zharsuat (\$872). The results of economic damage calculations are summarized in Table 3 .

As seen from the table above, the economic damage from cancer cases was calculated by summing up the cost of treatment, per capita GDP loss due to temporary disability, sick leave and social disability payments.

The cost of state expenditures per single cancer case treatment was averaged depending on the stage of the disease. For example, at stage 1 or 2 the average cost of treatment was KZT200,000, at stage 3 the cost of treatment escalates to KZT1 mln., while at stage 4 the treatment cost reaches KZT20 mln [17].

The situation is similar with respect to average length of disability due to illness. For instance, at stage 1 or 2 the average disability is as long as 2 months, while at stage 3 to 4 the length of disability extends to 6 months [18].

When calculating the economic damage we calculated the Social Security Disability payments (disability welfare) as well. In 2012 the annual social disability payments amounted to KZT173,030. This study identified some $50 \%$ of patients to be welfare recipients (patients in stage 3 or 4) [16,17].

It should be noted that following the introduction of a screening program in 2011, which was designed to detect cancer cases early on, we have observed an outburst of primary cancer cases among exposed population when looking back to prior years. Albeit, an in-depth study revealed the cause of the burst being not the increased primary incidence, but the higher level of early detection compared to prior years. For instance, some $50 \%$ of cases were diagnosed at early stage (1 or 2) [18].

\section{Uncertainties}

This study involves a number of uncertainties, starting with gathering of primary material, and all way down to up to the assessment of the actual economic damage. In particular, we believe that domestic hygienic standards for measuring harmful air substances, intended for short period averaging, need to be validated for legality of their use for long period averaging (average annual maximum permissible concentrations (MPCs)) for chronic effect evaluation purposes. For instance, the Hydromet LTD report on benzene monitoring says that daily measurements were taken 4 times a day and averaged at 6 hour intervals. At the same time back in 2008 the European Union did already adopt the Directive "On ambient air quality and cleaner air for Europe", according to which establishing the MPCs for human health protection purposes, the reliable data's proportion should be $75 \%$ of one-hour value, i.e. 45 minutes. In

Table 1. IRIS vs Guidelines.

\begin{tabular}{|c|c|c|c|c|c|}
\hline \multirow{3}{*}{ Chemical } & \multicolumn{2}{|c|}{ Guidelines } & \multicolumn{3}{|c|}{ IRIS } \\
\hline & \multirow{2}{*}{$\begin{array}{c}\text { RfC } \\
\mathrm{mg} / \mathrm{m}^{3}\end{array}$} & \multirow{2}{*}{$\begin{array}{c}\text { URi } \\
\text { per } \mathrm{mg} / \mathrm{m}^{3}\end{array}$} & \multirow{2}{*}{$\begin{array}{c}\text { RfC } \\
\mathrm{mg} / \mathrm{m}^{3}\end{array}$} & \multicolumn{2}{|c|}{ URi } \\
\hline & & & & per $\mu g / m^{3}$ & per $\mathrm{mg} / \mathrm{m}^{3}$ \\
\hline benzene & 3.00E-02 & 7.71E-03 & $3.00 \mathrm{E}-02$ & $7.80 \mathrm{E}-06$ & 7.80E-03 \\
\hline
\end{tabular}

Source: References $[4,15]$

Table 2. Carcinogenic risk assessment from annual average concentrations of benzene due to the KOGCF air emissions (2012).

\begin{tabular}{|c|c|c|c|c|c|}
\hline Selected villages & $\begin{array}{c}\text { Average annual } \\
\text { population }\end{array}$ & $\begin{array}{l}\text { Average annual benzene } \\
\text { concentrations }(\mathrm{mg} / \mathrm{m} 3)\end{array}$ & Unit risk, Uri $\left(\mathrm{mg} / \mathrm{m}^{3}\right)$ & Individual cancer risk & PCRa \\
\hline $\begin{array}{l}\text { Berezovka (including } \\
\text { Uspenovka) }\end{array}$ & 1650 & 0.1 & 0.008 & $7.80 \mathrm{E}-04$ & 0.02 \\
\hline Priuralni & 1353 & 0.1 & 0.008 & 8.00E-04 & 0.02 \\
\hline $\begin{array}{l}\text { Zharsuat (including } \\
\text { Zhanatalap) }\end{array}$ & 1738 & 0.1 & 0.008 & $7.80 \mathrm{E}-04$ & 0.02 \\
\hline Kiziltal (including Bestau) & 4250 & 0.1 & 0.008 & 7.90E-04 & 0.05 \\
\hline
\end{tabular}


Citation: Kenessary DU, Kenessary AU, Kenessariyev UI, et al. Carcinogenic risk assessment of benzene from the oil and gas field. Environ Risk Assess Remediat. 2017;2(1):11-15

Table 3. Annual economic damage from additional cancer incidence (2012).

\begin{tabular}{|c|c|c|c|c|c|}
\hline Rural health clinic & Berezovka & Priuralni & Zharsuat & Kiziltal & Total \\
\hline PCRa & 0.02 & 0.02 & 0.02 & 0.05 & 0.1 \\
\hline Economic damage, US\$ (EDmorb) & 844 & 689 & 872 & 2123 & 4529 \\
\hline 1. State treatment expenses (TC) & 678 & 553 & 700 & 1704 & \\
\hline stage $1-2$ & 13 & 10 & 13 & 32 & \\
\hline$T C_{1-2}$ & 1333 & 1333 & 1333 & 1333 & \\
\hline$k_{c 1-2}$ & 0.5 & 0.5 & 0.5 & 0.5 & \\
\hline stage 3 & 32 & 26 & 33 & 80 & \\
\hline$T C_{3}$ & 6667 & 6667 & 6667 & 6667 & \\
\hline$k_{c 3}$ & 0.25 & 0.25 & 0.25 & 0.25 & \\
\hline stage 4 & 633 & 517 & 654 & 1592 & \\
\hline$T C_{4}$ & 133333 & 133333 & 133333 & 133333 & \\
\hline$k_{c 4}$ & 0.25 & 0.25 & 0.25 & 0.25 & \\
\hline 2. Sick leave payment (SIC) & 4 & 3 & 4 & 9 & \\
\hline$S I C_{\max }$ & 185.2 & 185.2 & 185.2 & 185.2 & \\
\hline 3. Disability welfare (SSC) & 13 & 11 & 14 & 33 & \\
\hline$b_{c}$ & 1384 & 1384 & 1384 & 1384 & \\
\hline$k_{c b}$ & 0.5 & 0.5 & 0.5 & 0.5 & \\
\hline 4. GDP deficit due to temporary disability (LGDP) & 150 & 122 & 155 & 377 & \\
\hline LGDP1-2 & 37 & 31 & 39 & 94 & \\
\hline LGDP 3-4 & 112 & 92 & 116 & 283 & \\
\hline$C G D P_{w}$ & 1973 & 1973 & 1973 & 1973 & \\
\hline$m_{c 1-2}$ & 2 & 2 & 2 & 2 & \\
\hline$m_{c 3-4}$ & 6 & 6 & 6 & 6 & \\
\hline
\end{tabular}

Comments: total cost denominated in the national currency tenge (KZT) was converted into USD at the exchange rate set by of the National Bank of Kazakhstan: KZT150 I USD1.

Source: cancer incidence in 2012 - reference [16]

a 24 -hour value (daily average), $75 \%$ of the average hour values (i.e., at least 18 hour values) [19]. In other words, the maximum one-time measured values must be averaged, per international regulations, at 45 minute intervals, while the daily average measures, at minimum 18-hour average, respectively.

Moreover, due to the lack of questionnaire data, the assessment of economic damage from cancer cases did not take into account the household treatment expenditures, nor moral or financial costs of sick-nursing.

There is no data on the percentage of smokers among the population exposed. As no surnames could be retrieved for additional benzene-related cancer cases and, consequently, to formulate the predictive probability of a patient's life expectancy, it was impossible to calculate the additional mortality from benzene-related cancer cases, and therefore to identify any kind of economic damage from those cases. So we had to calculate the economic damage solely based on additional cancer cases during a year.

\section{Discussion}

According to the American Cancer Society the cancer has the most devastating economic impact of any cause of death in the world. In 2008, causing 83 million years of "healthy life" lost due to premature death and disability from carcinogenic diseases, worldwide cancer accounted for nearly a trillion dollars in economic losses, which is about $1.5 \%$ of world's GDP. The economic toll from cancer is nearly 20 percent higher than heart disease, the second leading cause of economic loss (\$895 billion vs. $\$ 753$ billion respectively) [20].
The National Institutes of Health (NIH) estimated the 2009 overall annual costs of cancer at $\$ 216.6$ billion. Direct medical costs (total of all health expenditures) were estimated at $\$ 86.6$ billion. Indirect mortality costs (cost of lost productivity due to premature death)- $\$ 130$ billion [21].

As expected, the impact is not evenly distributed among the nations. For instance, while the US has the highest economic loss from cancer in absolute monetary term, the disease costs the country $1.73 \%$ of its GDP. But cancer in Hungary, with its much smaller population and domestic economy, takes an economic toll that is $3.05 \%$ of its GDP. Twenty-five nations are losing more than $2 \%$ of their GDP to deaths and disability caused by cancer. The WHO and global health experts believe that significant costs from cancer could be mitigated by targeted, cost-effective interventions [22].

Though cancer incidence in the RoK is increasing rapidly, the human health risk caused by pollution of the human environment by carcinogenic chemicals is neither assessed, nor managed properly. Therefore this exact study might be a sufficient contribution for the commencement of human health carcinogenic risk assessment and mangement activities throughout the Kazakhstan.

\section{Conclusions}

Actual annual growth of additional cancer incidence was found to be 0.1 cases per 9 thousand population. The economic damage from additional cancer incidence due to benzene KOGCF emissions in 2012 equaled $\$ 4,530$.

Still it is necessary to harmonize the rules of primary gathering of material (chemical concentrations) with international standards and regulations, such as the EU Directive. 
Yet, since the annualized population carcinogenic risk of benzene concentrations for total exposed population was less than one case, we advise against making executive decisions on reducing concentrations. Nonetheless we do recommend continuous perennial monitoring of benzene in the studied area. Furthermore, the annual human health economic damage assessment must be made mandatorily, on a legal basis, whenever an industrial facility runs its operations associated with the air pollution. And the results of economic damage assessment from KOGCF emissions must be included as an expense item in the statutory payments made by an enterprise to the government, to rehabilitate the health of the exposed population, within the framework of the Free Public Health Care system.

\section{References}

1. Kenessariyev UI. Hygienic basis of assessment prognosses and development of environmental-health system at KOGCF. [dissertation]. Almaty (RoK);1993.

2. Anambayeva AI. Hygienic assessemnt and prognosis children health of KOGCF region. [dissertation]. Almaty (RoK);1999.

3. Kurmangaliev OM. Ecological and hygienic aspects of forming pathology of the genitourinary system in RoK oila nd gas condensate regions (on an example of KOGCF). [dissertation]. Almaty (RoK);2008.

4. http://ohranatruda.ru/ot_biblio/normativ/data_ normativ/46/46715/index.php

5. http://adilet.zan.kz/rus/docs/P1200000093

6. Kenessary AU. Medical and organizational aspects of development of measurements for decreasing negative impact of environment pollution (water, air, soil) on human health (on the example of KOGCF) [dissertation]. Almaty (RoK);2011.
7. http://www.inchem.org/documents/iarc/suppl7/benzene. html

8. http://www.thelancet.com/journals/lanonc/article/ PIIS1470-2045(09)70358-4/fulltext

9. http://aje.oxfordjournals.org/content/153/5/433.long

10. http://link.springer.com/article/10.1023\%2FB\%3AEN MO.0000020889.41526.66

11. Kenessariyev UI, Dosmukhametiv AT, Amrin MK, et al. Human health risk assessment in oil and gas condensate region. Vestnik KazNMU. 2012;(1):334-36.

12. http://www.epa.gov/risk_assessment/glossary.htm

13. http://online.zakon.kz/Document/?doc_id=30155616

14. http://www.epa.gov/IRIS/

15. Burlin central district hospital Statistics Division. Data on the primary morbidity and demographic indicators in 2012.

16. http://ztgzt.kz/actual/recommended-reading/derzhiteravnovesie.html

17.http://online.zakon.kz/Document/?doc_id=31150652

18. file://localhost/C:/Users/user/Downloads/1-Казахстан\%20 в\%202012\%20году.pdf

19. http://online.zakon.kz/Document/?doc_id=30986389

20.http://eur-1ex.europa.eu/legal-content/EN/ TXT/?uri=CELEX:32008L0050

21.http://www.cancer.org/acs/groups/content/@ internationalaffairs/documents/document/acspc-026203.pdf

22. http://www.cancer.org/cancer/cancerbasics/economicimpact-of-cancer

\section{*Correspondence to:}

Kenessary DU

Kazakh National Medical University

Almaty

Republic of Kazakhstan

Kazakhstan

Tel: +77475009000

E-mail:dku999@mail.ru 